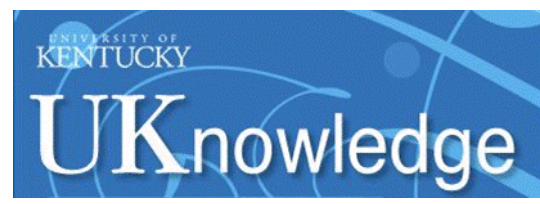

University of Kentucky

UKnowledge

$10-2012$

\title{
Envisioning an Oral Healthcare Workforce for the Future
}

David A. Nash

University of Kentucky, danash@uky.edu

Follow this and additional works at: https://uknowledge.uky.edu/ohs_facpub

Part of the Dentistry Commons

Right click to open a feedback form in a new tab to let us know how this document benefits you.

\section{Repository Citation}

Nash, David A., "Envisioning an Oral Healthcare Workforce for the Future" (2012). Oral Health Science Faculty Publications. 8.

https://uknowledge.uky.edu/ohs_facpub/8

This Article is brought to you for free and open access by the Oral Health Science at UKnowledge. It has been accepted for inclusion in Oral Health Science Faculty Publications by an authorized administrator of UKnowledge. For more information, please contact UKnowledge@lsv.uky.edu. 


\section{Envisioning an Oral Healthcare Workforce for the Future}

\section{Digital Object Identifier (DOI)}

http://dx.doi.org/10.1111/j.1600-0528.2012.00734.x

\section{Notes/Citation Information}

Published in Community Dentistry and Oral Epidemiology, v. 40, issue supplement s2, p. 141-147.

All rights reserved. (C) 2012 John Wiley \& Sons A/S

This is the peer reviewed version of the following article: Nash, D. A., Envisioning an Oral Healthcare Workforce for the Future (2012) Community Dentistry and Oral Epidemiology, 40 (Suppl. 2): 141-147, which has been published in final form at http://dx.doi.org/10.1111/j.1600-0528.2012.00734.x. This article may be used for non-commercial purposes in accordance with Wiley Terms and Conditions for Self-Archiving. 
This is the peer reviewed version of the following article: Nash, D. A., Envisioning an Oral Healthcare Workforce for the Future (2012) Community Dentistry and Oral Epidemiology, 40 (Suppl. s2): 141-147, which has been published in final form at http://dx.doi.org/10.1111/j.1600-0528.2012.00734.x. This article may be used for non-commercial purposes in accordance with Wiley Terms and Conditions for Self-Archiving. 


\section{Envisioning an Oral Health Care Workforce for the Future}

Festschrift in Honor of Professor John Spencer

Australian Research Center for Population Oral Health

School of Dentistry

Faculty of Health Sciences

University of Adelaide

David A. Nash, D.M.D., M.S., Ed.D.

William R. Willard Professor of Dental Education

Professor of Pediatric Dentistry

College of Dentistry

University of Kentucky

Email: danash@email.uky.edu 


\begin{abstract}
Health is critical to human well-being. Oral health is an integral component of health. One is not healthy without oral health. As health is essential to human flourishing, it is important that an oral health care delivery system and workforce be developed and deployed which can help ensure all citizens have the potential to access oral health care. As such access does not generally exist today, it is imperative to advance the realization of this goal, and to develop a vision of an oral health care workforce to functionally support access. Public funding of basic oral health care is an important element to improving access. However, funding is only economically feasible if a workforce exists that is structured in a manner such that duties are assigned to individuals who have been uniquely trained to fulfill specific clinical responsibilities. An essential element of any cost-effective organizational system must be the shared responsibility of duties. Delegation must occur in the oral health workforce if competent, cost-effective care is to be provided. Desirable members of the oral health team in an efficient and effective system are: generalist dentists who are educated as physicians of the stomatognathic system (oral physicians), specialist dentists, dental therapists, dental hygienists, dually trained hygienists/therapists (oral health therapists), oral prosthetists (denturists), and expanded function dental assistants (dental nurses).
\end{abstract}




\section{Envisioning an Oral Health Workforce for the Future}

\section{Introduction}

Health is a state of physical, mental, and social well-being, not merely the absence of disease or infirmity. ${ }^{1}$ Health is a critical dimension of human well-being; a requisite for individuals to realize their full potential and to flourish as human beings. Health is a basic human good. Oral health is an integral and critical component of general health and well-being. ${ }^{2}$ One is not healthy without oral health.

Health care by competent health care workers is necessary for humans to gain and maintain optimal health. As the World Health Organization's Working Together for Health: The World Health Report, 2006, states: "Developing capable, motivated, and supported health workers is essential for overcoming bottlenecks to achieve national and global health goals. Health care is a labor-intensive service industry... at the heart of every health system, the workforce is central to advancing health." 3 The development and deployment of a well-trained, comprehensive, multifunctional oral health care workforce is an imperative for the oral health of a population.

\section{Assumptions}

1. Oral health is a component of general health and well-being; one is not healthy without oral health.

2. The stomatognathic system is integrally linked functionally to all organ systems and oral disease has an effect on general health.

3. Comparable to the care of other human functional organ systems, caring for the stomatognathic system is an essential component of primary health care.

4. There is an increasingly aging population with chronic diseases, and expanding numbers of individuals seeking oral health care who are biologically and/or pharmacologically compromised.

5. Conceptually, the practice of dentistry is the practice of medicine-oral medicine.

6. The importance of general health and well-being to society must ultimately result in universal access to basic oral health care to treat the infections of dental caries and periodontal disease, as well as debilitating developmental oral conditions.

7. Societal resources are, and will continue to be constrained, requiring a cost-effective health care delivery system; including one for oral health care.

The oral health care delivery system, and thus the oral health workforce, must be re-envisioned as a result of the forgoing assumptions. 


\section{Conceptual Foundations for Envisioning an Oral Health Care Workforce}

The eminent free market theorist, Adam Smith, in The Wealth of Nations, drew a distinction between social goods and consumer goods. ${ }^{4} \mathrm{He}$ argued that for a market economy to function, it must be based on a foundation of what he called social goods. Among identifiable foundational social goods are safety, security, education, and health. Such social goods were for Smith outside the marketplace and not subject to the forces of supply and demand. Rather, they were seen as basic human needs and imperatives to be met by a society in order for a marketplace to even exist. It is difficult to imagine a market-based economy surviving without citizens having a strong sense of personal safety and security, a basic education in the cognitive skills necessary to function in the marketplace, and the physical health - including oral health - with which to work. Health, including a decent, basic minimum of oral health is a social good, not a consumer good. Seeking oral health care is not analogous to purchasing an automobile or buying a television. Oral health care, basic care that is not elective, care that is focused on preventing and/or eliminating oral disease, is not a commodity to be purchased in the marketplace. To accept basic oral care as a consumer good is to accept the access problem to oral health care that exists today.

Professor Kenneth Arrow of Stanford University won the Nobel Prize in economics in 1972, partly because of his ability to demonstrate that health care cannot be considered a commodity of the marketplace, due to the complexity of knowledge that creates a significant power differential between health professional and patient. This circumstance precludes the patient being able to correctly determine the relationship between the cost of care and its value - a requisite for a marketplace transaction. ${ }^{5}$

The distinguished medical educator and ethicist, Edmund Pellegrino, in an article in The Journal of Medicine and Philosophy, concluded, "Health care is not a commodity, and treating it as such is deleterious to the ethics of patient care. Health is a human good that a good society has an obligation to protect from the market ethos."

Basic oral health care for both children and adults, as a social good, should be publicly financed; with care being provided in school-based programs and public health clinics, as well as privately owned community practices. Such care includes preventive services, the elimination of pain and infection, the restoration of carious teeth, and the replacement of missing teeth that are essential to mastication and/or socially acceptable appearance. There are a number of oral health care therapies that are beyond those deemed essential to basic oral health. These include, but are not limited to, such procedures as implants, fixed prostheses, orthodontics specifically for improved esthetics, and porcelain veneers for esthetics. Cost considerations would generally dictate that such procedures be a component of the private economy. Children are society's most vulnerable population. Should financial constraints seriously limit basic oral health care for all, moral arguments dictate that children must receive priority consideration. ${ }^{7,8}$

The primary focus of a system of oral health care must be the prevention of oral disease. Population-based approaches to prevention are the most cost effective; therefore, communityoriented preventive strategies are to be preferred. These include: community water fluoridation, salt fluoridation, community oral health education and promotion programs, community-based fluoride varnish applications, fluoride dentifrice distribution, and community-based dental 
sealant applications. Many of these community programs should be school-based. However, since dental caries affects pre-school children, preventive strategies must also be focused on pregnant mothers, infant care programs, and pre-school programs.

Public funding of basic oral health care can only be economically feasible if a workforce exists that is structured in such a manner that duties are assigned to individuals who have been uniquely trained to fulfill specific clinical responsibilities. An essential element of any cost-effective organizational system must be the delegation of duties. The oral health workforce is not immune this organizational imperative. Delegation of an appropriate level of clinical care responsibilities must occur if cost-effective care is to be provided. Expressed alternatively, members of the oral health care workforce should not be over-trained for the clinical responsibilities they must assume. A further economic issue is that members of the workforce should not be providing care that can be delegated to another member of the clinical team who has less training, but who can competently provide required care. Furthermore, as much autonomy as possible must be provided members of the workforce based on their competency. Such delegation and autonomy will result in less expense to the delivery system.

\section{Profiles of Potential Members of an Oral Health Care Team}

A comprehensive oral health care team consists of: generalist dentists; specialist dentists, dental therapists and dental hygienists (in some circumstances integrated in function and designated an oral health therapist); oral prosthetists (denturists); and expanded function dental assistants (designated dental nurses in some countries). Additional supportive personnel, though not involved directly in clinical patient care are dental laboratory technicians, and community oral health workers.

\section{Dentists}

Increasingly, it is being understood that dentists, as currently educated, are not as well-grounded in the basic bio-medical sciences as required, given the advances in scientific knowledge. Cellular and molecular approaches to diagnosing and treating disease are revolutionizing health care. To apply modern science the dentist must understand modern science in a way dental curricula do not permit. The increasingly aging population, and the expanding numbers of medically and/or pharmacologically compromised individuals, require that dentists understand clinical medicine at a scope and depth that is not typically achieved in current dental curricula. ${ }^{9}$ Bruce Baum has called the "inadequate training in the biological sciences and medicine for dental students....an impending crisis." 10 The dentist of the future must be a clinical scientist, having strong foundations in the basic biomedical sciences; understanding clinical medicine at a level of sophistication not different than any other specialist in medicine; possessing sound critical thinking skills, and using scientifically validated evidence in practice. No longer is it desirable or acceptable that dentists focus on being skilled technicians - such is necessary, but not sufficient.

Dental Education at the Crossroads: Challenges and Change, a major study of dental education in the United States by the Institute of Medicine, recommended that to prepare for more 
medically-based modes of oral health care, as well as caring for increased numbers of healthcompromised patients, dental education should become more "closely integrated" with medical education; this in order that student dentists could receive the same foundational education in the basic biomedical sciences as medical students. Additionally, the report called for student dentists to receive more training in clinical medicine. ${ }^{9}$

There is a movement to educate and train dentists more deeply and broadly in science and medicine. The Netherlands has transitioned its curriculum in dentistry from five academic years to six years, in order to develop dentists who are better educated to adapt to the changing landscape of science, and better trained in clinical medicine in order to provide safe and effective care for their patients. ${ }^{11}$

A more judicious approach for enhancing the education of dentists in science and in clinical medicine is for education in dentistry to be integrated completely with medical education in such a manner that the aspiring dentist would earn a degree in medicine concurrently with earning a credential in dentistry. Such education would conceptualize the dentist as a specialist in medicine, a "physician of the stomatognathic system," or "oral physician. ${ }^{12}$

The World Health Organization report, Oral Health for the $21^{\text {st }}$ Century stated: "The changing disease patterns, the advanced diagnostic and treatment methodologies and the broadening of responsibilities illustrate the need for a new type of oral health professional, someone with special education and skills in the care of the oral and maxillofacial complex. These professionals will have principal responsibility for oral health care, and they may be assisted by specially-trained support personnel. In addition to these generalist oral physicians it is anticipated that the need will remain for specialists." ${ }^{13}$

I have called for such a major transformation of dental education by developing a curriculum in which individuals desiring to become dentists are educated with individuals desiring to function in one of the other specialties of medicine. Such an approach underscores that dentistry is medicine--oral medicine--and a legitimate specialty within medicine. Such a system was designed for the University of Kentucky, and had it have been able to be implemented, would have resulted in individuals preparing for dentistry being able to complete the expectations for both a D.M.D. degree and an M.D. degree in a five year curriculum, versus the traditional four year D.M.D. program. (In the United States, four years of liberal arts education in the university is required prior to entering the study of dentistry.) An "oral physician" approach to dental education is analogous to the stomatological curriculum formerly employed in some European countries, which resulted in a stomatologist or physician/dentist. ${ }^{14} \mathrm{~A}$ relatively recent study of professors at Spanish dental schools who had taught in the stomatological curriculum prior to the introduction of the odontological curriculum in Spain in 1987, and continued to teach in the odontological curriculum subsequently, indicated strong preference for the value of a stomatological approach in preparing dentists for clinical practice. ${ }^{15}$

Training dentists in the same context as physicians will have the further beneficial effect of educating physicians generally to the nature, value, and importance of oral health as a dimension of overall health. Economic analysis of such a strategy indicates that integrating dental education with medical education has the positive circumstance of reducing the costs of what is typically 
one of our universities most expensive programs - dentistry. ${ }^{16}$ It is unlikely that oral health will ever be understood as a basic component of general health and well-being as long as education for dentistry exists outside the educational and cultural mainstream of physicians learning to care for other functional organ systems.

Some problems of oral health are exceedingly complex and require sophisticated therapy beyond the scope of a generalist dentist. Thus training programs must be developed for specialist dentists. Specialty training programs generally require two to five years of advanced education. Among the specialty areas recognized in dentistry in at least some countries are: oral and maxilla-facial surgery, orthodontics, pediatric dentistry, periodontology, endodontics, prosthodontics, oral pathology, oral radiology, and public health dentistry. Additional specialty fields may emerge in the future based on scientific advances and increasing sophistication of techniques.

\section{Dental Therapists}

Dental therapists evolved in New Zealand, and the use of therapists has spread to many other countries of the world. ${ }^{17}$ Over fifty countries have been identified that utilize dental therapists. ${ }^{18}$ Dental therapists, originally designated school dental nurses, have traditionally worked in the public sector (government-funded) in school settings, providing basic oral health care for children under the general supervision of a dentist. Procedures generally included in the scope of practice of dental therapists include the full repertoire of preventive therapies, the restoration of primary (deciduous) and young permanent teeth with appropriate biomaterials, performance of pulpotomies, placement of stainless steel crowns, and extraction of primary (deciduous) teeth. Traditionally, therapists have been trained in a two academic year program. ${ }^{19}$ Recently, in some jurisdictions of some countries, dental therapists are permitted to work in the offices of dentists in the private sector, or in their own offices, with consultant arrangements with dentists, and in some instances to provide basic care for adults. ${ }^{20,21}$

Experience has demonstrated that quality preventive and rehabilitative oral health care for children can effectively and efficiently be provided by dental therapists working in school-based clinics. $^{22,23,24}$ Such a strategy should be the priority for an oral health care delivery system. Treatment of children with special needs requiring advanced care beyond the scope of practice of dental therapists can be referred to generalist or specialist dentists. In remote and underserved areas, where access to a generalist dentist is not possible, dental therapists may be required to provide basic oral health care for adults.

\section{Dental Hygienists}

Dental hygienists are integral members of the oral health care team. ${ }^{25}$ Traditionally, hygienists have worked in the private sector in the offices of dentists, and have devoted their time and attention to preventive periodontology; specifically oral health education and promotion, and the scaling and polishing of teeth. ${ }^{26}$ There is an increasing tendency to combine the training of dental therapists and dental hygienists in a three year curriculum in order that they may function in either or both roles, that is, prevention and treatment of both periodontal disease and dental caries. These individuals have become designated as oral health therapists. ${ }^{27}$ In recent reforms of 
its oral health delivery system, The Netherlands has added the traditional skills of the dental therapist to the practice profile of its dental hygienists, and has increased the number of individuals being trained annually by $43 \%$, to 300 each year. At the same time the number of dentists being matriculated in Holland has been reduced by $20 \%$, and as previously indicated the curriculum increased from five to six years. This major reform is based on the rationale that in the future, significant aspects of basic preventive and restorative care will be provided by hygienists/therapists, with dentists performing more complex procedures, and caring for increasing numbers of health-compromised patients. ${ }^{11}$

A potential issue in combining the training of therapists with hygienists is that therapists have traditionally worked in the public sector with children, while hygienists have worked in the private sector with adults. Should such a tendency continue, it could result in individuals being trained to perform duties that they do not routinely accomplish. Dual education adds to the cost of training, and ultimately to the cost of care, if both scopes of practice are not utilized by an individual so trained. This issue has recently been identified as a potential problem in New Zealand. $^{28}$

\section{Oral Prosthetists}

Oral Prosthetists (Denturists or Clinical Dental Laboratory Technicians) are members of the oral health care workforce who are able to fabricate, either with or without the prescription of a dentist (depending on regulations of jurisdictions), removable prosthetic appliances (partial and full dentures) to replace missing teeth. ${ }^{29}$ The length of training varies throughout the world, from 18 months to three years. Due to the reduced length of training, denturists are members of the oral health care workforce who are able to provide a required oral health service more economically than a dentist. Replacement of missing teeth with partial or complete dentures should be delegated to oral prosthetists to enable dentists to provide the level of care that only they are educated and trained to provide.

\section{Expanded Function Chair-side Dental Assistants (Dental Nurses)}

Expanded function chair-side dental assistants (dental nurses) are important members of the oral health care team. ${ }^{30.31}$ Their work is typically associated with a clinician working in the dental operatory/surgery. They are able to assist the dentist, therapist, and hygienist by both preparing and passing instruments, performing procedures that are preparatory to therapy, and in completing procedures that have been initiated, thus permitting team members to perform more efficiently and effectively. Duties that can be delegated to expanded function chair-side dental assistants (varying by jurisdiction) include: exposing radiographs, polishing teeth, placing fissure sealants, applying fluoride varnish, and restoring teeth with biomaterials in cavities prepared by the dentist/therapist/hygienist.

Ideally, all members of the oral health care workforce should be trained in a common setting. Doing so would enable team members to understand the role and value of their respective colleagues. However, accomplishing this will be challenging as some members of the dental 
team are educated in a university setting, and others trained in a vocational/technical school environment.

\section{Conclusions}

1. Oral health is a critical and integral dimension of general health and well-being.

2. Basic, primary oral health care must become a funded component of a nation's health care system in order for all citizens to have access to oral health care.

3. The development and deployment of a well-educated oral health care workforce is essential for a population to access care.

4. Prevention of oral disease is an ultimate goal and is to be desired above rehabilitative therapy. Therefore, priority consideration should be given to funding and implementing all appropriate preventive strategies.

5. When financial resources are constrained, moral arguments dictate funds should be allocated to preventing and treating oral disease in children.

6. A comprehensive oral health team consists of: dentists who are educated as physicians of the oral cavity; specialist dentists; therapists and hygienists (or a combination of the two-an oral health therapist); oral prosthetists (denturists); and expanded function dental assistants/dental nurses.

7. To ensure that dentists are competent to apply scientific evidence and knowledge of clinical medicine in their practices, and to ensure that their level of expertise is equivalent to physicians caring for other organ systems, dental education should be merged with medical education. Such a strategy has the desirable effect of helping to ensure that oral health is understood as an integral dimension of general health. Integration also has the potential for a more economical approach to educating for dental practice.

8. Finally, in order to ensure that a cost-effective approach to universal access to basic oral health care is possible, duties must be assigned to individuals on the oral health care team who are prepared to competently provide the required care; and care must be taken to ensure that individuals are not over-trained for the role they play.

The profession of dentistry, collaborating with society, has a moral obligation to develop a delivery system and workforce that is able to offer access to basic, quality oral health care for all. Visionary, bold, courageous, and effective leadership is required if this responsibility is to be fulfilled. That mantle of leadership falls to each of us. 


\section{References}

1. World Health Organization, www.who.org Accessed June 30, 2011.

2. American Dental Association. The oral-systemic connection: An update for the practicing dentist. A special supplement to the Journal of the American Dental Association. J Am Dent Assoc 2006;137:1S-40S.

3. World Health Organization, Working together for health: The world health report 2006. Geneva, Switzerland.

4. Smith A. An inquiry into nature and causes of the wealth of nations, 1776. Indianapolis: Liberty Classics; 1981.

5. Arrow KJ. Uncertainty and the welfare economics of medical care. The American Economic Review 1963;53(5):941-73.

6. Pellegrino ED. The commodification of medical and health care: the moral consequences of a paradigm shift from a professional to a market ethic. The Journal Of Medicine And Philosophy 1999;24(3):243-66.

7. Kopelman LM, Palumbo MG. The U.S. health delivery system: inefficient and unfair to children. Am J Law Med 1997;23(2-3)319-37.

8. Daniels N. Equity and population health: Toward a broader bioethics agenda. Hastings Cent Rep 2006;36(4):22.

9. Field M. Dental education and the crossroads: challenges and change. Institute of Medicine, National Academy of Sciences, National Academy Press, Washington, D.C., 1995.

10. Baum BJ. Inadequate training in biological sciences and medicine for dental students: an impending crisis for dentistry. J Am Dent Assoc 2007;138:16-26.

11. Innovation in dental care: recommendations, Secretariat of the Innovation in Dental Care Committee, the Institute for Research on Public Expenditures (IOO), Leiden, The Netherlands, February, 2006.

12. Nash DA. The oral physician: creating a new oral health professional for a new century. $\mathbf{J}$ Dent Educ 1995;59:587-597.

13. World Health Organization. Oral health for the $21^{\text {st }}$ century. Geneva, April, 1994.

14. Hobdell M et al. Stomatology and odontology. In: Shanley, D, ed. Dental Education in Europe. Dublin: DentEd Thematic Network Project 2001: 140-146.

15. Seoane J. Diz-Dios P. Martinex-Insua A. Varela-Centelles P. Nash DA. Stomatology and Odontology: Perspectives of Spanish professors and senior lecturers in dentistry. Eur J Dent Educ 2008;12:219-224.

16. Nash DA. And the band played on... J Dent Educ 1998;62(12):964-974.

17. Fulton JT. Experiments in dental care: results of New Zealand's use of school dental nurses. World Health Organization, Geneva, Switzerland, 1951

18. Nash D. Friedman J. Kardos T. Kardos R. Schwarz E. Satur J. Berg D. Nasruddin J. Mumghamba EG. Davenport ES. Nagel R. Dental therapists: a global perspective. Int Dent J 2008; 58(2)61-70.

19. Nash, DA. Developing a pediatric oral health therapist to help address oral health disparities in children. J Dent Educ 2004;68(1):8-20.

20. Satur J. A new oral health professional-The oral health therapist. Oral health therapy programs in Australia and New Zealand, Tsang, AKL, editor. Knowledge Books and Software, Queensland, Australia, 2010 
21. Nash, DA. Improving access to oral health care for children by expanding the dental workforce to include dental therapists. Dent Clin N Am 2009;53:469-483.

22. Roder DM. The effect $t$ of treatment provided by dentists and school dental therapist in the South Australian School Dental Service. Aust Dent J 1973;18(5):311-19.

23. Roder DM. The effect of treatment provided by dentists and school dental therapist in the South Australian School Dental Service. The Second Report. Aust Dent J. 1976;21(2):147-52.

24. Roder DM. Diagnosis, treatment planning and referral by school dental therapists. Aust Dent J. 1974;19(4):242-49.

25. Johnson P. International profiles of dental hygiene 1987 to 2001: A 19-nation comparative study. Int Dent J 2003: 53:299-313.

26. Nash DA. Expanding dental hygiene to include dental therapy: Improving access to care for children. J Dent Hyg 2009;84(1):36-44.

27. Tsang AKL. Editor, Oral health therapy programs in Australia and New Zealand. Knowledge Books and Software, Queensland, Australia, 2010

28. New Zealand Ministry of Health. Ministry of Health (Oral Health Team) Initial Response to the 2009 New Zealand Oral Health Survey Findings. Report to the Oral Health Workforce Executive Forum , 15 February, 2011.

29. Tuominen R. Removable dentures provided by dentists, denturists and laboratory technicians. J Oral Rehabilitation 2003: 30:55-59.

30. Lotzkar S. Johnson D. Thompson M. Experimental program for expanded functions for dental assistants: phase one, baseline, and phase two, training. J Am Dent Assoc 1971: 82:1067-81.

31. Abramowitz J. Berg LE. A four year study of the utilization of dental assistants with expanded functions. J Am Dent Assoc 1973;87(3):623-35. 